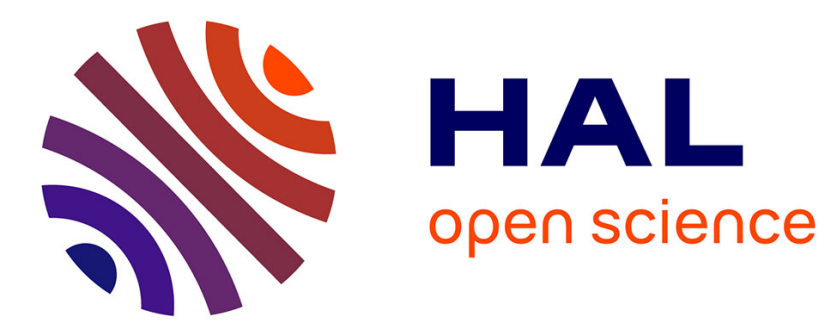

\title{
Deposition of titanium-based films by laser-assisted thermal CVD of titanium tetrachloride
}

\author{
R. Alexandrescu, R. Cireasa, B. Dragnea, I. Morjan, I. Voicu, A. Andrei
}

\section{To cite this version:}

R. Alexandrescu, R. Cireasa, B. Dragnea, I. Morjan, I. Voicu, et al.. Deposition of titanium-based films by laser-assisted thermal CVD of titanium tetrachloride. Journal de Physique IV Proceedings, 1993, 03 (C3), pp.C3-265-C3-272. 10.1051/jp4:1993336 . jpa-00251393

\section{HAL Id: jpa-00251393 https://hal.science/jpa-00251393}

Submitted on 1 Jan 1993

HAL is a multi-disciplinary open access archive for the deposit and dissemination of scientific research documents, whether they are published or not. The documents may come from teaching and research institutions in France or abroad, or from public or private research centers.
L'archive ouverte pluridisciplinaire HAL, est destinée au dépôt et à la diffusion de documents scientifiques de niveau recherche, publiés ou non, émanant des établissements d'enseignement et de recherche français ou étrangers, des laboratoires publics ou privés. 


\title{
Deposition of titanium-based films by laser-assisted thermal CVD of titanium tetrachloride
}

\author{
R. ALEXANDRESCU, R. CIREASA, B. DRAGNEA, I. MORJAN, I. VOICU and A. ANDREI* \\ Laser Department, Institute of Atomic Physics, Bucharest MG-6, 76900, Romania \\ * Institute for Nuclear Research, Pitesti, Romania
}

\begin{abstract}
The results of a study of laser-assisted CVD of thin titanium films from $\mathrm{TiCl}_{4}$ using a $\mathrm{CO}_{2}$ laser are pesented. The Ti-based layers deposited onto quartz substrates were investigated by XPS technics. The influence of the incident laser energy on the chemical content of films as well as on the film growth rate was pointed out. The experimental results indicate that, on quartz substrate a multilayer structure is formed with unsaturated $\mathrm{TiSi}_{X}$ at the interface and oxidized phases at the surface.
\end{abstract}

\section{INTRODUCTION}

Compared to conventional techniques, surface selectivity, high purity and rapid film formation may be often achieved in processes related to laser induced thermal CVD of thin metal films, characterized by substrate surface heating by the laser beam and subsequent pyrolytic decomposition of adsorbed reactant molecules, [1],[2].

Titanium and titanium alloys layers are mainly requested either in large-area depositions, for protection and corrosion resistant coatings, or in the formation of film microstructures, for optical waveguides and microelectronic devices. In this last case, titanium film have been used to improve metal to substrate adhesion while titanium silicides and nitrides are of interest for diffusion barriers, interconnections, Ohmic contacts [3],[4] , and so on. Titanium is also used in biomedical applications as it is non-toxic for human body [5]. $\mathrm{TiCl}_{4}$ was used as a precursor for the laser deposition of $\mathrm{Ti}$ films, either in a pyrolitic [6], or UV-photolytic process [7]. It was observed [1], that in the investigations using $\mathrm{TiCl}_{4}$ for laser induced deposition of titanium, film purities were not reported.Besides, to our knowledge, there has been no attempt to carry out titanium films deposition from titanium (IV) tetrachloride by a $\mathrm{CO}_{2}$ laser-induced CVD process.

The purpose of this paper was to study the $\mathrm{CO}_{2}$ laser-assisted CVD of tianium films from $\mathrm{TiCl}_{4}$, with special emphasis on an overall analysis of the purity of the as-deposited 
film. Transmission measurements at different wavelengths were used in order to evaluate the film thickness and the deposition rate. Using X-ray photoelectron spectroscopy (XPS) a study of the evolution of film composition with increasing laser energy was performed.

I was revealed that:

i) the films were $\mathrm{Cl}$ - free;

ii) the titanium content of films increases with increased laser power;

iii) the film consists of a complex multilayer structure, with unsaturated $\mathrm{TiSi}_{X}$ formation at the interface and oxidized phases at the surface.

\section{EXPERIMENTAL}

The irradiation of $\mathrm{TiCl}_{4}$ was conducted at room temperature and the $\mathrm{TiCl}_{4}$ vapour pressure of $\cong 10$ Torr. The radiation of an unfocused $\mathrm{cw} \mathrm{CO}_{2}$ laser (maximum output power $55 \mathrm{~W}$ ) was directed perpendiculary to the quartz substrate, which temperature rise was monitored through a Pt-Rh thermocouple mounted on the back side of the plate. The substrates were mounted on ceramics holders to prevent heat diffusion during irradiation.

Using an electrical chopper with variable pulse length and frequency, the changes induced in both film composition and thickness for different irradiation regimes were investigated (table 1).

\section{Table 1}

Irradiation regimes.

\begin{tabular}{|llllll|}
\hline Laser power , $\mathrm{P}($ Watt): & 18 & 18 & 18 & 18 & 22 \\
Pulse length, $\mathrm{L}_{\mathrm{p}}(\mathrm{ms}):$ & 6.3 & 13.3 & 13.3 & 6.25 & 6.25 \\
Frequency, $\mathrm{f}(\mathrm{Hz})$ & 7.14 & 7.14 & 13.3 & 80 & 80 \\
$\begin{array}{l}\text { Deposited energy, } \mathrm{E}(\mathrm{J}) \text { in } \mathrm{t}=300 \mathrm{~s} \\
\text { irradiation time *) }\end{array}$ & 243 & 513 & 955 & 2700 & 3300 \\
\hline
\end{tabular}

*) Cycles of $10 \mathrm{~s}$ irradiation time were separated by $5 \mathrm{~s}$ shut intervals, in order to avoid large temperature gradients in the substrate.

For the irradiation regimes listed above, the recorded overall substrate temperatures ran between $650^{\circ} \mathrm{C}$ and $1000^{\circ} \mathrm{C}$. To note that the experiments, in which the laser energies were exceeding the maximum value in Table 1, progressive damage of the surface occured.

A He-Ne laser was used to monitor the thickness of films deposited at different laser energies. IR transmission measurements performed in the transparency region of the quartz substrates allowed to estimate the dependence of film thickness and deposition rate on effective irradiation time, $t$ (cumulative time in which the sample was "seen" by the laser beam): $t=\tau \times f \times L_{p}$.

The thickness of deposited films was measured by interference microscopy (approximate accuracy level, 1/20 of the visible light wavelength). 
The chemical composition of films was analysed by electron spectroscopy photoelectron spectra were obtained with a VG-ESCALAB MK-II- spectrometer (base pressure about $9 \times 10^{-10} \mathrm{mbar}$ ). For XPS, the unmonochromatized $\mathrm{Al} \mathrm{K} \alpha$ radiation (hv $=$ $1486.6 \mathrm{eV}$ ) was used.

Spectra of $01 s$, Ti2p, Si $2 p$, were recorded. A "flood gun" was used for the correction of charging effects taking as a reference the position of the $C 1 \mathrm{~s}$ line at 284.6 $\mathrm{eV}$ (carbon contamination in films).

\section{RESULTS AND DISCUSSION}

$\mathrm{TiCl}_{4}$ vapor is strongly adsorbed on the all internal walls of the reaction cell. A large adsorbed layer is expected to be formed on the substrate, when the vapor pressure is reached [8]. Since $\mathrm{TiCl}_{4}$ is transparent to the $10.6 \mathrm{~mm}$ radiation, the film growth occurs through the laser induced thermal decomposition and/or reaction of this adsorbed $\mathrm{TiCl}_{4}$ layer, which is constantly renewed in the interval between pulses.

The optical transmission measurement at the He-Ne probe laser radiation, showed an increase in the absorbtivity of films obtained at increased laser energies (Fig.1).

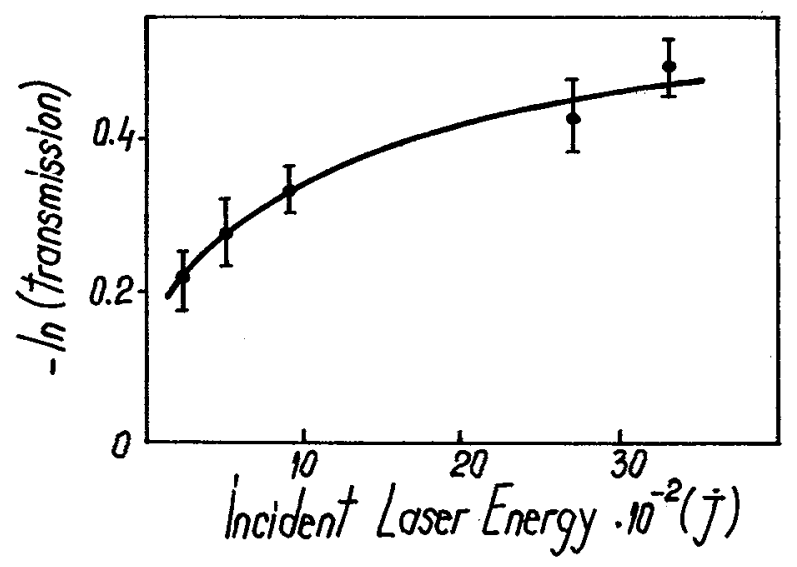

Fig.1. The transmission of the deposited films as a function of incident laser energy.

From a nearly linear dependence at a low laser fluence, the film transmission has a much smaller increase at high laser fluence indicating a mass transport limited process.

From IR transmission measurements, the film thickness and the deposition rate were inferred, using the Lambert-Beer law for different IR wavelength and the numerical differentiation relatively to the effective irradiation time (fig.2). The measured films were produced at different deposition stages, characterized by variable irradiation time intervals and a constant power density. The results plotted in Fig. 2 were obtained by relating the calculation to the experimental values of the film thickness, as measured by interferential microscopy method (the error bars take into account the limitations of this method). 


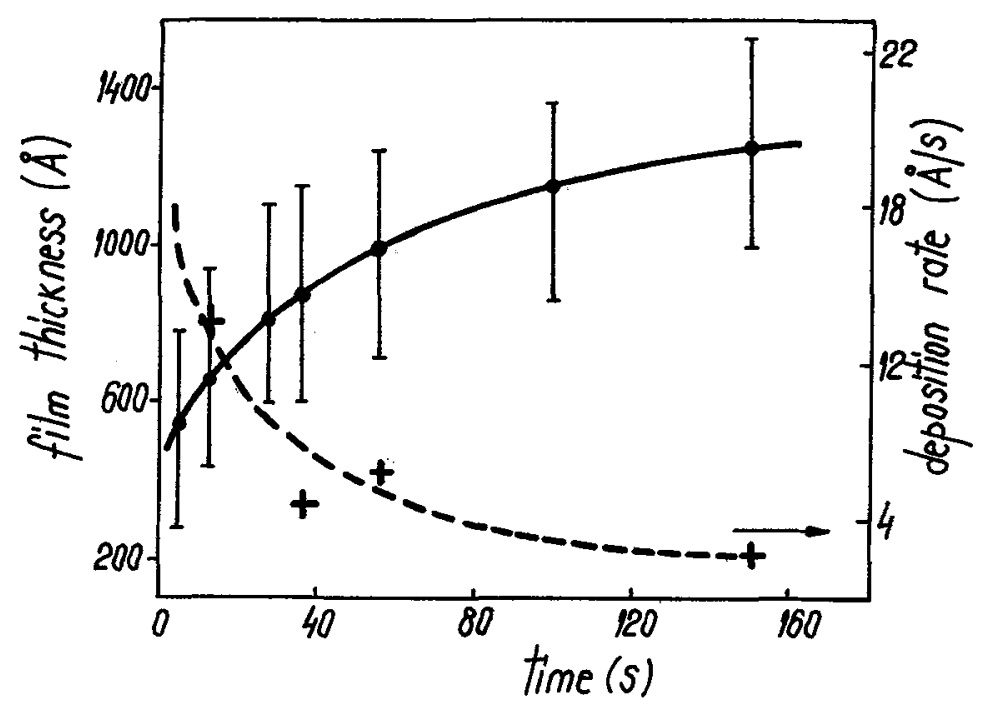

Fig. 2 Film thickness (circles)and deposition rate (crosses) vs. effective irradiation time

From Fig.2, the film thickness varies from $550 \AA$ in 5.0 s irradiation time to $\sim 1250 \AA$ for 150.0 s, while the deposition rate decreases from $14 \AA / s$ (for $15 \mathrm{~s}$ ) to $2.5 \AA / s$ (for $150 \mathrm{~s}$ ).

The chemical composition of the surface layers of deposited films, as determined by XPS analysis included as well $\mathrm{Ti}$ and $\mathrm{O}$, as different quantities of silicon. The presence of chlorine has not been revealed,indicating that $\mathrm{Cl}$ resulted from $\mathrm{TiCl}_{4}$ decomposition, is efficiently eliminated by thermal desorption.

The evolution of composition of films obtained at five different irradiation regimes show that, with increasing incident laser energies, the total Ti content (in atomic percent) of films is growing, while there is a decrease in Si content of the surface layers, (Fig.3).

It has been shown [5], [8-11] that at temperatures $700-1000^{\circ} \mathrm{C}$ a reaction between $\mathrm{Ti}$ and $\mathrm{SiO}_{2}$ takes place, resulting in a multilayer structure with interfacial mixting of the dominant titanium silicide at the $\mathrm{SiO}_{2}$ interface and the graded titanium oxidized phases at the surface.

As will be further shown, there is obviously a thickening of the (oxidized) Ti films deposited on quartz substraates with the increase laser power density, together with a lowered contribution from $\mathrm{TiSi}_{X}$ layer as deduced also from Fig. 3 .

Fig. 4 displays the typical double structure of the Ti $2 p$ line, for samples obtained at variable laser energies. The main peak, which for the sample a (deposited at $500 \mathrm{~J}$ laser energy) lies at $458.6 \mathrm{eV}$, is associated with a highly oxidized Ti state, corresponding to a sub $\mathrm{TiO}_{2}$ valence, [8]. This peak is shifted towards $459 \mathrm{eV}$ with increasing laser energy (see curve d in Fig.4) indicating a nearly stoichiometric $\mathrm{TiO}_{2}$ formation. At the same time, there is a narrowing of the line shape, pointing out to a diminished contribuition of intermediate oxidized species $\mathrm{TiO}_{x}$, which interfere at the low energy side of the $\mathrm{Ti} 2 \mathrm{p}$ line. 


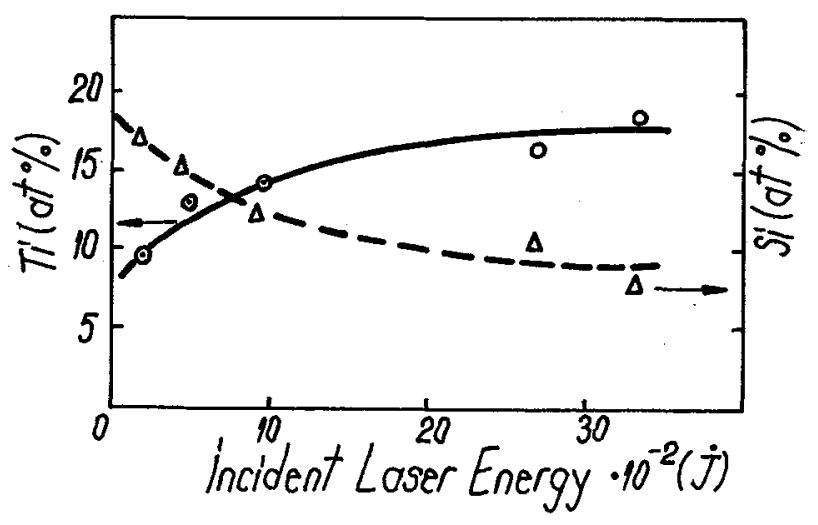

Fig. 3 XPS results (in atomic percent) for the evolution of the total Ti(o) and Si( $\Delta$ ) content of samples, with increasing incident laser energies.

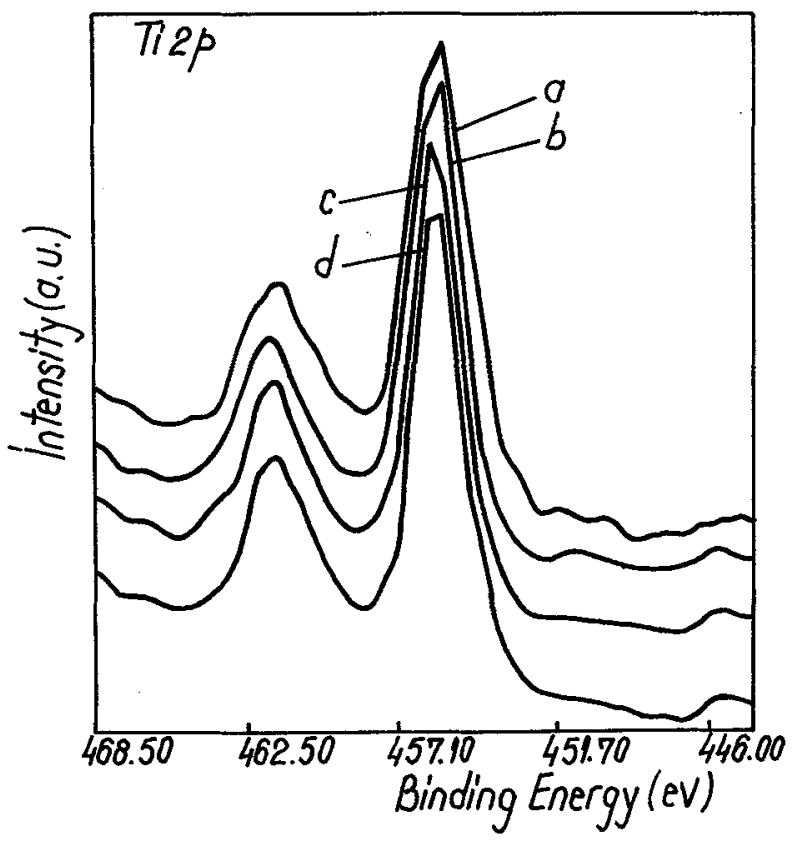

Fig. 4 XPS spectra for the Ti $2 p$ line. The samples were obtained at different deposition laser energies: curve a, 513J; curve b, $955 \mathrm{~J}$; curve c, $2700 \mathrm{~J}$; curve d, $3300 \mathrm{~J}$ 
According to literature data [8], a contribution of a $\mathrm{TiSi}_{x}$ component lies also on the low energy side of the $\mathrm{Ti} 2 p$ line, with binding energy close to (but lower than) the oxidized $\mathrm{TiO}_{x}$ phases. Using a deconvolution technique ("peak synthesis") contribution for the sample a is evidenced at $456 \mathrm{eV}$ (Fig.5).

From Fig. 4 and Fig. 5 one may observe:

i) the partial overlapping of the energies attributed to $\mathrm{TiSi}_{x}$ and $\mathrm{TiO}_{\mathrm{X}}, \mathrm{x}<2$, components and ii) the decrease contribution of the $\mathrm{TiSi}_{x}$ (interfacing at the low energy side of spectra) with increasing laser power density.

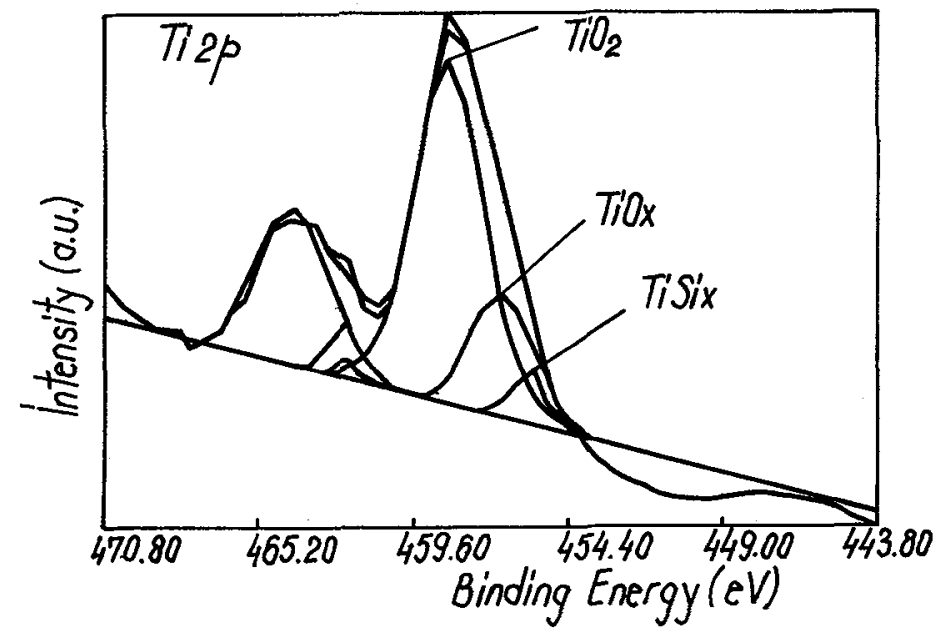

Fig. $5 \mathrm{Ti} 2 \mathrm{p}$ doublet and its deconvolution for film grown at $513 \mathrm{~J}$ laser energy (sample a in Fig. 4). The three components of the $\mathrm{Ti}_{2} 2 p_{3 / 2}$ line are attribuated to $\mathrm{TiO}_{2}(458.6 \mathrm{eV}), \mathrm{TiO}_{X}$, $x<2,(456 \mathrm{eV})$ and $\mathrm{TiSi}_{x}(455.2 \mathrm{eV})$

The Si $2 p$ line of the films spectra deposited at variable laser energies (indicated at Table 1) shows a peak at $99.8 \mathrm{eV}$ which may be attributed to Si bound in $\mathrm{TiSi}_{\mathrm{X}}[8]$ (Fig.6). The same line shows a double structure in the case of the deposited films at high laser densities $\left(\mathrm{P}_{\max } \sim 55 \mathrm{~W}\right)$, in which case, due to the local damage of the substrate, Si-O bonds at $103 \mathrm{eV}$ are evidenced (Fig.6).

The $01 \mathrm{~s}$ line spectra of samples shows a double structure in which the peak at $530.6 \mathrm{eV}$ may be attributed to the heavily oxidized surface titanium species, while the peak at $532.6 \mathrm{eV}$ is due to the chemisorbed oxygen.

It is well known that the films of $\mathrm{Ti}$ are extremely reactive to oxygen, either during the deposition or after the exposure to ambient atmosphere. We believe that in our experimental conditions the oxidation effect is primarily a result of the deposition process in which the oxygen released at the silicidation reaction of $\mathrm{Ti}_{\text {with }} \mathrm{SiO}_{2}$ (the quartz substrate) plays an essential role in the kinetics of the growing Ti-based layers. 


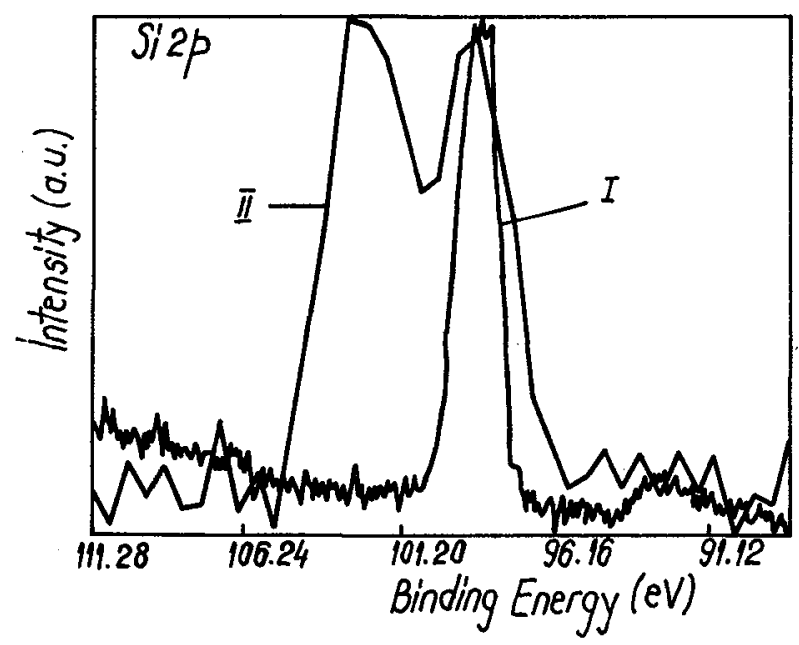

Fig. 6 The Si $2 p$ line spectra for a typical deposited film-curve I (laser power, 18.22 W) and for a locally melted deposit-curve II (laser power, $55 \mathrm{~W}$ )

For an interpretation of the XPS data on surface analysis, one must keep in mind that the information is obtained from a depth region of the $\sim 60 A$ (the inelastic mean free path of electrons in titanium oxide is $\sim 15-18 \AA$ [13]). I this respect it is worthwhile to note the XPS detection of silicon (either bounded to Ti or in elemental form) diffused towards the surface (Figs.3, 5 and 6) which was already observed in Auger [8] and XPS [10] depth profiles of annealed $\mathrm{Ti}$ on $\mathrm{SiO}_{2}$.

All the data exposed above point out to a complex dynamical behaviour of the growing film components, characterized by different reaction kinetics. Then, we propose the following mechanism which is consistent with the experimental data:

i) Titanium may be formed by local heating and subsequent thermal decomposition of $\mathrm{TiCl}_{4}$ layer adsorbed on surface (decomposition of $\mathrm{TiCl}_{4}$ was observed at $600^{\circ} \mathrm{C}$-see [7] and references herein):

1) $\mathrm{TiCl}_{4} \rightarrow \mathrm{Ti}+2 \mathrm{Cl}_{2}$

ii) The contact of freshly formed Ti with the quartz substrates at temperatures above $700^{\circ} \mathrm{C}$ is leading to bond breakage of the $\mathrm{Si}-\mathrm{O}$ in $\mathrm{SiO}_{2}$, by a redox type reaction, in which the metal is oxidized while the quartz is reduced [5]:

2) $11 \mathrm{Ti}+3 \mathrm{SiO}_{2} \rightarrow \mathrm{Ti}_{5} \mathrm{Si}_{3}+6 \mathrm{TiO}$.

In equation 2, metal-rich silicide and $\mathrm{TiO}$ are likely to be formed as an intermediate layer at $\mathrm{Ti}$-SiO interface, due to the lack of $\mathrm{Si}$ and $\mathrm{O}$ atoms, in comparison to $\mathrm{Ti}$ atoms [9].

iii) Alternatively, the reduction of $\mathrm{SiO}_{2}$ is liberating oxygen which indiffuses in the Ti layer and forms graded oxidized phases, from $\mathrm{TiO}_{\mathrm{x}}(\mathrm{x}<2)$ to nearly stoichiometric $\mathrm{TiO}_{2}$ towards the surface. It was shown [8] that, although at a lower extent, silicon is also diffusing. 
probably reacting with $\mathrm{Ti}-\mathrm{O}$ and giving $\mathrm{TiSi}_{\mathrm{x}}$, which in low concentration extends up to the surface (Figs. 3 and 5).

iv) As the film grows, XPS analysis detects changes in the dynamics of film formation. The decreasing of the $\mathrm{TiSi}_{x}$ component (observed in Figs. 3 and 4) may be due to a thicker interfacial $\mathrm{Ti}_{5} \mathrm{Si}_{3}$ layer, which could screen the quartz substrate from direct Ti contact. At the same time, an increased contribution from heavily oxidized Ti species at the surface (Fig. 4) is observed: there is evidence in the literature [12] of induced decomposition of oxygen-defficient $\mathrm{TiO}_{x}$ in the presence of $\mathrm{Ti}$ at $\sim 400^{\circ} \mathrm{C}$, which could provide adequate oxygen to make more stoichiometric $\mathrm{TiO}_{2}$ layer.

In conclusion, the investigation of the laser-induced of Ti-based films from titanium tetrachloride evidenced the formation of a multicomponent layer, which formation originates in reactions of $\mathrm{Ti}$ with the quartz substrate at the interface. Besides graded oxidized $\mathrm{TiO}_{\mathrm{x}}$ phases, XPS analysis revealed the presence of a TiSi $x$ component. The dependence of the $\mathrm{Ti}$ content of layers on irradiated power was determined.

\section{REFERENCES;}

1. T.H.Baum, P.B.Comita, Thin Solid Films, 1-2,(1992), 80

2. S.D.Allen, R.Y.Jan, S.M.Mazuk, S.D.Vernon, Appl.Phys. 58, (1985), 327

3. E. d'Anna, G.Leggieri, A.Luches, Thin Solid Films, 1-2 (1992), 95

4. N.Yokoyama, K.Hinode, Y.Homma, J.Electrochem.Soc., I,(1991), 190

5. S.L.Sung, J.Y.Chee, E.W.Merrill, Ceramic Transaction, vol.11, (Ceramic Thin and Thick Films), (1990), 153

6. J.Y.Tsao, R.A.Becker, D.J.Ehrlich, F.J.Loenberger, Appl.Phys.Lett., 42, (1983), 558

7. C.Lavoie, M.Meunier, S.Boivin, R. lzquierdo, P.Desjardins, Appl.Phys, A53, (1991), 339

8. H.Bender, W.D.Chen, J.Portillo, L.Van den Hove, W.Van der Vorst, Appl.Surf.Sci. 38, (1989), 37

9. C.C.Hsu, You-Xiang Wang, Shi-Duat Yin, Boo-Qi Li, Ming-Ron Ji, Jian-Xin Wu,J.Vac.Sci.Tehnol.,A5(4), (1987), 1402

10. C.P.Lofton, W.E.Swartz, Thin Solid Films, 52, (1978), 271

11. J.S.Maa, C.J. Lin, J.H.Liu, Thin Solid Films, 64, (1979), 439

12. A.R.Nyalosh, E.L.Garwin, F.K.King, R.E.Kirby, J.Vac.Sci.Tech. A4(5), (1986), 2356

13. D.Briggs, M.P.Sean, edits., Practical Surface Analysis, vol.1: Auger and X-ray Photoelectron Spectroscopy, John Wiley and Sons Ltd., (1990). 